\title{
Emprendimiento y economía informal: caracterización empírica de la empresa española a partir de los datos del Global Entrepreneurship Monitor
}

Instituto Tecnológico y de Estudios Superiores de Monterrey carmen.lafuente@itesm.mx

Ignacio López Domínguez ${ }^{2}$ Universidad Complutense de Madrid ilopezdo@ucm.es

DOI: https://doi.org/10.21158/01208160.n84.2018.1915

Carlos Poza Lara ${ }^{3}$

Fecha de recepción: 05 de agosto de 2017

Fecha de aprobación: 28 de octubre de 2017

Cómo citar este artículo / To reference this article / Comment citer cet article / Para citar este artigo:

Lafuente Ibáñez, C.; López Domínguez, I. y Poza Lara, C. (2018). Emprendimiento y economía informal: caracterización empírica de la empresa española a partir de los datos del Global Entrepreneurship Monitor. Revista EAN, 84, (pp 15 -41). DOI: https://doi.org/10.21158/01208160.n84.2018.1915

\section{Resumen}

El objetivo de este trabajo es describir y analizar el perfil de las empresas españolas que ejercen su actividad dentro de la economía informal, utilizando el método directo de la encuesta proveniente de la base de datos Global Entrepreneurship Monitor (GEM). Para ello, se ha llevado a cabo una revisión del concepto y métodos de estimación de la economía informal, así como una comparativa internacional para contextualizar la situación española. Así mismo, se ha utilizado un modelo de regresión logística para identificar las características que explican los diferentes niveles de economía informal en España. Los resultados muestran que las empresas nacientes, constituidas por necesidad, creadas por emprendedores menores de 42 años y pertenecientes al sector servicios, presentan una mayor probabilidad de operar en la economía informal. La región donde se constituye la empresa y el nivel de renta del emprendedor también influyen en los niveles de economía informal.

\section{Palabras clave}

Economía informal, emprendimiento, Global Entrepreneurship Monitor, perfil del emprendedor informal, España.

\footnotetext{
${ }^{1}$ Doctora en Ciencias Económicas y Empresariales en la especialidad de Métodos Cuantitativos por la UNED (España). Licenciada en Ciencias Económicas y Empresariales por la Universidad de Zaragoza. En la actualidad es profesora de Econometría en el Tecnológico de Monterrey.

${ }^{2}$ Doctor y Licenciado en Ciencias Económicas y Empresariales, Universidad Autónoma de Madrid. Profesor de la Universidad Complutense de Madrid (Departamento de Administración Financiera y Contabilidad. Coordinador Académico de la asignatura Fundamentos de Administración Financiera de la Empresa. Vicepresidente de la Asociación Internacional de Estudios sobre Management (ASIEMA). Consultor Asociado del Centro de Liderazgo Internacional.

${ }^{3}$ Doctor en Ciencias Económicas y Empresariales por la Universidad Complutense de Madrid. Máster Universitario en Análisis del Entorno Económico por la Universitat Oberta de Catalunya. Experto Universitario en Análisis de Datos en Investigación Social y de Mercados. Licenciado en Economía (Universidad CEU-San Pablo).
} 


\section{Entrepreneurship and informal economy. empirical description of the spanish company based on data provided by Global Entrepreneurship Monitor}

Abstract. This paper aims at describing and analyzing the profile of the Spanish company which performs its activities within an informal economy scheme, applying the survey method from the date base GEM-Global Entrepreneurship Monitor. Consequently, a general review of concepts and methods about the estimation of informal economy, as well as an international comparison to contextualize the current Spanish situation. At the same time, a model of logistic regression has been applied to describe the features which clearly explain different levels of informal economy in Spain. Its outcomes show that new-born companies stablished by necessity and formed by entrepreneurs younger than 42 years old which belong to the services sector tend to operate under an informal economy scheme. The region where the company is stablished and the rent level of the entrepreneur also influences on its level of informal economy.

Key words: informal economy, entrepreneurship, Global Entrepreneurship Monitor, informal entrepreneur profile, Spain.

\section{Entrepreneuriat et économie informelle. Caractérisation empirique de l'entreprise espagnole à partir des données du Global Entrepreneurship Monitor}

Résumé. L'objectif de cet article concerne la description et l'analyse du profil des entreprises espagnoles opérant dans l'économie informelle grâce à l'analyse sous forme d'enquête de la base de données Global Entrepreneurship Monitor -GEM. Nous avons ainsi réalisé un examen du concept et des méthodes d'estimation de l'économie informelle et effectué une comparaison internationale pour contextualiser la situation en Espagne. Un modèle de régression logistique a également été utilisé pour identifier les caractéristiques expliquant les différents niveaux de l'économie informelle en Espagne. Les résultats de cette étude montrent que les nouvelles entreprises, créées par nécessité et par des entrepreneurs de moins de 42 ans appartenant au secteur des services, sont davantage susceptibles d'opérer dans l'économie informelle. Le lieu d'établissement de l'entreprise et le niveau de revenu de l'entrepreneur influencent également les niveaux de l'économie informelle.

Mots clefs: économie informelle, entrepreneuriat, Global Entrepreneurship Monitor, profil d'entrepreneur informel, Espagne.

\section{Empreendimento e economia informal. Caracterização empírica da empresa espanhola a partir dos dados do Global Entrepreneurship Monitor}

Resumo. O objetivo deste trabalho é descrever e analisar o perfil das empresas espanholas que exercem sua atividade dentro da economia informal, utilizando o método direto do questionário proveniente da base de dados Global Entrepreneurship Monitor, GEM. Para isso, se realizou uma revisão do conceito e métodos de estimativa da economia informal, bem como uma comparativa internacional para contextualizar a situação espanhola. Também se utilizou um modelo de regressão logística para identificar as características que explicam os diferentes níveis de economia informal na Espanha. Os resultados mostram que as empresas nascentes, constituídas por necessidade, criadas por empreendedores menores de 42 anos e pertencentes ao setor serviços apresentam uma maior probabilidade de operar na economia informal. A região onde se constitui a empresa e o nível de renda do empreendedor também influenciam os níveis de economia informal.

Palavras-chave: economia informal, empreendimento, Global Entrepreneurship Monitor, perfil do empreendedor informal, Espanha. 


\section{Introducción}

$\mathbf{L}$ a crisis financiera internacional, los problemas de deuda soberana en Europa y la recesión económica española de los últimos años han provocado un aumento -o al menos un afloramiento- de la economía informal en España, sin precedentes que, lógicamente, ha agitado el interés de los investigadores en estudiar sus causas, sus consecuencias, su medición y las posibles soluciones al problema.

En esta línea, cabe destacar una serie de estudios españoles como los del Círculo de Empresarios (2010) y la Fundación de Cajas de Ahorros -Funcas- (Arrazola, Hevia, Mauleón y Sánchez, 2011), pero también los resultados publicados por la Organización para la Cooperación y el Desarrollo Económicos -OCDE- (Schneider, 2015), quien ha realizado un importante esfuerzo por establecer una definición homogénea y acotada de la economía sumergida y la economía informal, y por constituir un ranking de países con mayores niveles de actividad en $\mathrm{B}$ entre las economías avanzadas.

Esta voluntad ha sido muy relevante porque existía una definición muy amplia, diversa y dispersa de la economía sumergida. En ocasiones, se hablaba de actividades legales no computadas y de actividades ilegales como la prostitución y las drogas, y en otros casos, solo de las primeras, más vinculadas a lo que tradicionalmente se ha entendido por economía informal.

Este trabajo se enmarca dentro de esta corriente de estudios sobre actividades legales no calculadas ni registradas, en el que a través de la medición directa se tratan de detectar los rasgos característicos de la empresa informal en España; en nuestro caso, a través de los cuestionarios de la base de datos del Global Entrepreneurship Monitor (GEM), que en 2012 dedicaron un special topic a la economía informal analizada desde el punto de vista de los emprendedores. Por tanto, el objetivo general de este trabajo es describir y analizar el perfil de las empresas españolas -emprendedores españoles-, que ejercen su actividad dentro de la economía informal utilizando el método directo de la encuesta proveniente de la citada base de datos GEM. Este objetivo general se concreta en los siguientes objetivos específicos:

- Revisar la conceptualización y métodos de medición del término economía informal.

- Describir y realizar un estudio comparativo de la situación de la economía informal en España en relación con la de los países de la OCDE.

- Identificar los rasgos del emprendedor informal en España.

- Determinar las características de la empresa informal a partir de los resultados de un análisis cuantitativo -descriptivo, inferencial y causal- de los datos del GEM.

Para abordar dichos objetivos, la presente investigación se estructura de la siguiente manera: en primer lugar, se realiza un repaso a las diferentes definiciones y métodos de estimación existentes sobre la economía informal; en segundo lugar, se describe el caso español tratando de ofrecer cifras comparativas de economía informal entre diversos métodos de cálculo y entre países; en tercer lugar, se detallan los

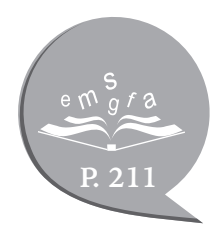


principales estudios que analizan el perfil del emprendedor que ejerce su actividad en la economía informal; en cuarto lugar, se describe la metodología de la investigación empleada para analizar los datos del GEM (2012); en quinto lugar, se presentan los principales resultados obtenidos de donde se deriva la caracterización de la empresa informal en España; y en última instancia, se realiza, a modo de conclusión, un resumen y discusión de los principales resultados conseguidos a lo largo de esta investigación.

\section{Conceptualización y medición de la economía informal}

$\mathbf{E}^{s}$ s importante conocer la naturaleza y la magnitud que la economía informal representa en la economía de un país. En este sentido, es necesario obtener estadísticas que permitan describir y cuantificar las características de este tipo de actividades que forman parte, en mayor o menor medida, de las economías de todos los países.

El conocimiento de la economía informal garantiza una mejor determinación del producto interior bruto (PIB) y del empleo de un territorio; y esto es fundamental

para la formulación y evaluación de políticas eficaces en apoyo a la transición hacia la formalidad, como herramienta de promoción dirigida a los grupos demográficos pertinentes, para determinar las tendencias nacionales y mundiales de empleo y para analizar los vínculos entre el crecimiento y el empleo (Oficina Internacional del Trabajo, s. f., p. 2).

La obtención de estadísticas exige una precisa conceptualización con respecto a qué se entiende por economía informal para poder realizar una adecuada medición.

El término informal fue introducido por Keith Hart a principios de la década de los 70 en un trabajo realizado en Ghana sobre desempleo urbano en África. En este trabajo, el autor asocia las oportunidades de ingreso informal a la figura del trabajador por cuenta propia.

En esta línea, la Organización Internacional del Trabajo (OIT) en la decimoquinta Conferencia Internacional de Estadísticos del Trabajo celebrada en 1993, se refiere a las empresas que operan en el sector informal como aquellas que no están registradas o son empresas privadas pequeñas pocos trabajadores, por ejemplo, menos de cinco; en cada país, se establece un umbral diferente- no constituidas que producen bienes o servicios para la venta o el trueque. El concepto empresa abarca a aquellas unidades que contratan a trabajadores y a trabajadores por cuenta propia o independiente.

Por otro lado, la OCDE se refiere a la economía sumergida como aquellas actividades económicas cuyo producto final es legal, que son escondidas deliberadamente a las autoridades públicas para evitar pagos -impuestos y seguridad social- procedimientos administrativos $\mathrm{o}$ requisitos mínimos legales, salarios mínimos, estándares de seguridad, etc.-. 
Aunque existen divergencias entre autores y fuentes sobre los conceptos de «economía sumergida» y «economía informal», a efectos de este trabajo se considerará como economía informal todas las actividades de trabajadores o unidades económicas que no están inscritas en el Registro de Actividades Económicas. Quedan excluidas de la economía informal todas las actividades delictivas como la producción y distribución de drogas, armas, etc.

En términos generales, se pueden considerar tres métodos para cuantificar la economía informal: métodos directos, indirectos y el método Mimic -multiple indicators \& multiple causes- (Tabla 1).

Tabla 1. Métodos de estimación de la economía informal

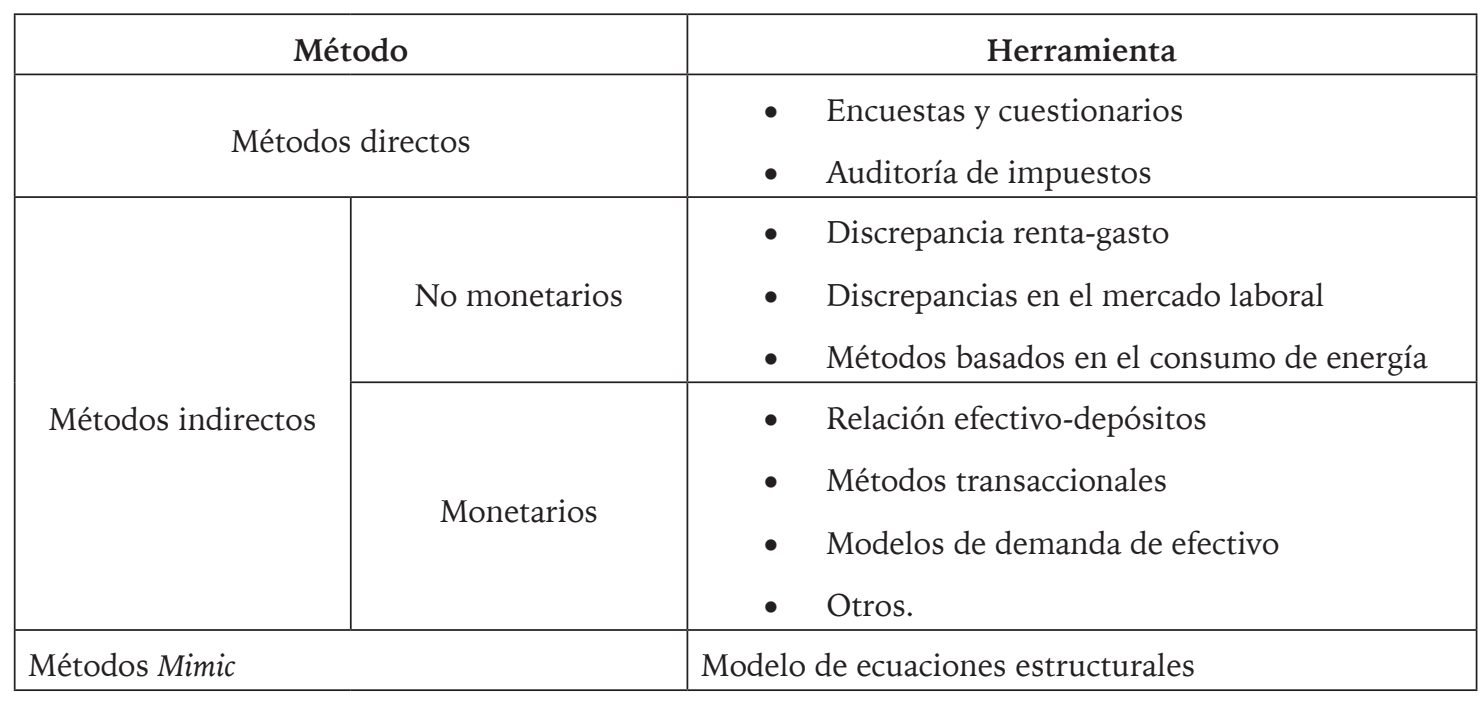

Fuente. Adaptado de Sardá (2014).

Los métodos directos intentan medir el tamaño de la economía informal a partir de la información recopilada con encuestas por muestreo. Este procedimiento se utiliza para la elección de unidades -muestra- dentro de un conjunto más amplio -población-, es decir, se realiza una consulta a un número representativo de trabajadores independientes y de unidades económicas que ejercen su actividad en un territorio concreto. Con los resultados que arroja la muestra, se realiza una estimación del volumen de economía informal que existe en la zona geográfica de estudio. La aplicación de esta técnica presenta ciertas limitaciones, además de las propias de su naturaleza, las derivadas de intentar cuantificar algo tan complicado, por su carácter oculto, como la informalidad.
Las encuestas presentan una serie de inconvenientes: el coste monetario y temporal, la dificultad de establecer una muestra representativa, la falta de cooperación de los agentes (la mayoría de las personas encuestadas van a esconder comportamientos fraudulentos o van a dar una estimación reducida o imprecisa de estos), la subjetividad en el diseño y elaboración del cuestionario, etc. Estos inconvenientes generan numerosas dudas sobre la fiabilidad y la credibilidad de este tipo de datos (Círculo de Empresarios, 2010, p. 20).

A pesar de estas limitaciones es una técnica utilizada en muchos países para cuantificar la dimensión de la economía informal. 
Los métodos indirectos son aquellos que tratan de analizar las diferencias entre el comportamiento observado de determinadas variables macroeconómicas y el comportamiento de esas mismas variables dentro de lo que se consideraría un escenario normal en una economía. Según Sardá (2014), aunque estos métodos no dependen de las opiniones de los encuestados, presentan limitaciones derivadas de los supuestos que hay que realizar para llevar a cabo la estimación.
Por último, el modelo Mimic, el cual utiliza como técnica de estimación los modelos de ecuaciones estructurales. En este caso, se trata de estimar el tamaño de la economía informal a partir de la influencia de determinadas variables que la causan y del impacto que dicha economía tiene sobre determinados indicadores económicos. Este método tampoco está exento de limitaciones, puesto que las estimaciones serán buenas si los datos son buenos y las especificaciones del modelo son adecuadas (Figura 1).

Figura 1. Modelo Mimic

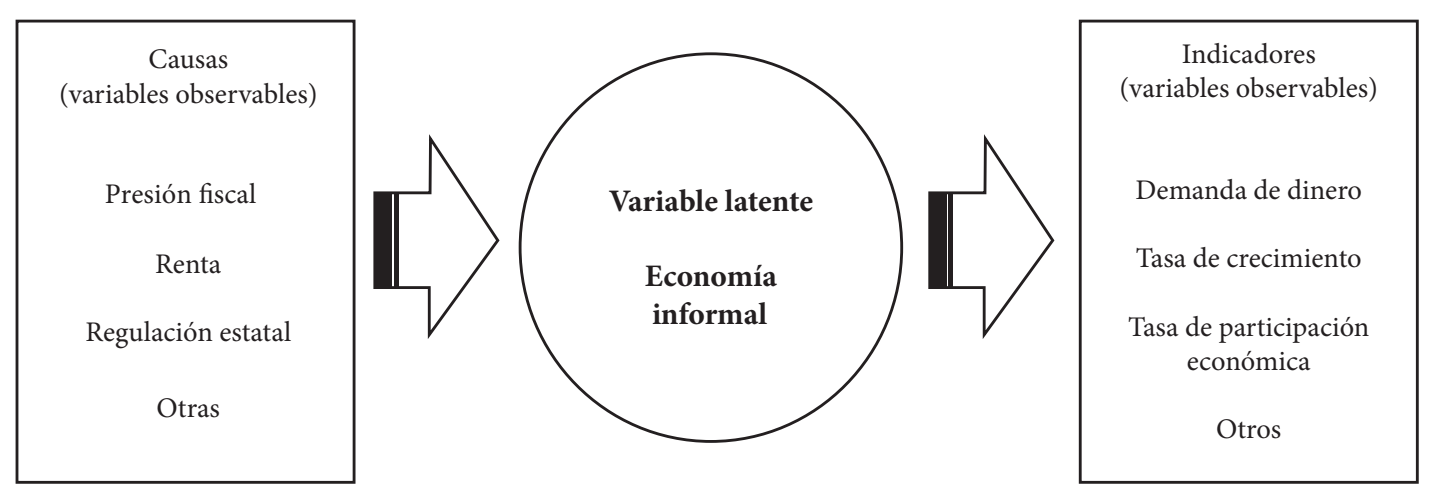

Fuente. Elaboración propia. 


\section{La economía informal en España}

$E_{\text {ir }}^{1}$ estudio del volumen de la economía nformal en España no es nuevo. Desde la década de los 80 se ha realizado un gran número de estudios cuyos resultados han sido de gran utilidad. Nos remitimos a Arrazola et al. (2011) para ver un valioso resumen de los principales trabajos y de sus resultados en los que se afronta la estimación de este tipo de economía en España, para centrarnos precisamente en la medición de esta variable en nuestro país.

El estudio de Arrazola et al. (2011) realiza tres aproximaciones alternativas: la monetaria, la que emplea el consumo de energía y la que emplea los modelos Mimic, para la estimación de la economía informal en España en el periodo 1980-2008. A continuación, se presentan los resultados más importantes.

El enfoque monetario arroja un incremento de la importancia de la economía informal sobre la economía oficial durante todo el periodo considerado. Dada la metodología empleada por el modelo monetario, gran parte de la responsabilidad de este aumento se adjudica al mantenimiento y crecimiento de la carga fiscal en el mismo periodo objeto de estudio.

El incremento de la presión fiscal y las cargas por la seguridad social es la primera razón argumentada en todas las investigaciones para la aparición, el mantenimiento y el aumento de la economía informal, tanto para el caso español (Pichardt y Sardá, 2015; Sardá y Mauleón, 1997) como para el resto de economías (Schneider, 1997, 2015; Schneider, Buehn y Montenegro, 2010). Otras causas que estos estudios señalan como razones explicativas de la aparición de la economía informal son incremento de la regulación -normas laborales que impiden la libre circulación de trabajadores, que establecen un salario mínimo o incluso que limitan la cuantía de las importaciones mediante barreras al comercio-, que impide a los individuos incorporarse a la economía oficial (Friedman, Johnson, Kaufmann y Zoido-Lobatón, 2000; Johnson, Kaufmann y Zoido-Lobatón, 1998); la economía informal reduce la recaudación pública vía impuestos, lo cual puede redundar en peores servicios públicos y a su vez incentivar a las personas a salir fuera de la economía formal al no ver justificado su pago de impuestos con la contraprestación recibida a través de servicios o infraestructuras públicas (Johnson et al., 1998); la propia situación de la economía oficial también influye en la informal, pues una economía en recesión muestra menores posibilidades a los trabajadores para su mejora salarial, situación que intentarán compensar mediante trabajos en la economía informal (Bajada y Schneider, 2005; Schneider y Enste, 2000; Feld y Schneider, 2010). De hecho, esto último puede generar un círculo vicioso, por tanto, una economía informal en expansión atraerá a más personas -extranjeras o nacionales-mediante esos incentivos y hará menos atractiva aun la economía formal (Schneider, 1997).

Para este modelo, en 2008, la proporción que representa la economía informal sobre el PIB oficial se situaría en torno al $21.29 \%$ -que partió del $11.69 \%$ en 1980 , con un máximo de 26.37 \% en 2007-.

De la aplicación del método no monetario basado en el consumo de energía en España durante el periodo 1980-2008, en consonancia con lo obtenido en el caso del modelo monetario, indica que el volumen de economía informal en términos relativos con respecto a la economía oficial se ha incrementado desde la

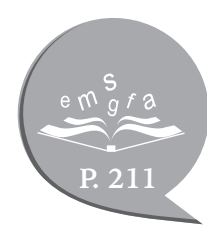


década de los 80. Por tanto, el aumento de la carga fiscal media en España vuelve a ser la causa estimada del aumento.

Según el modelo de energía, la proporción de la economía informal en España respecto del PIB ha pasado del $11.69 \%$ en 1980 hasta el $18.47 \%$ en 2008 , y alcanzó el punto máximo en 2007, con un $21.23 \%$ (Arrazola et al., 2011).

El método Mimic vuelve a arrojar incrementos de la informalidad en España durante el periodo objeto de estudio. Según este modelo, en 1980, el peso de la economía informal era de $11.69 \%$ del PIB. En 2008, ese porcentaje pasó al $21.79 \%$, siendo el punto más alto de la serie histórica (Arrazola et al., 2011).

A continuación se presentan las estimaciones de la proporción que supone la economía informal sobre la oficial, obtenidas a partir de los tres métodos (Figura 2). A pesar de que se aprecian diferencias puntuales entre las diferentes estimaciones, es indudable que existe a grandes rasgos una evolución muy semejante para las estimaciones realizadas a partir de los tres procedimientos. Igualmente, muestra una enorme semejanza en la evolución a largo plazo de las diversas aproximaciones realizadas para la economía informal en España, una evolución creciente determinada, sin duda, por el aumento de la presión fiscal. A este respecto, cabe destacar que el aumento del peso de la economía informal sobre la economía oficial ha tenido lugar en un contexto de fuerte crecimiento medio de la actividad económica oficial.

Cabe señalar igualmente que todos los estudios sobre la economía informal en España, aunque puedan diferir, escasamente, sobre su importancia, sí que coinciden plenamente en señalar una tendencia creciente a largo plazo (Lafuente, 1980; Moltó, 1980; Sardá y Mauleón, 1997); aunque también hay que señalar que dicha tendencia alcista se da la vuelta si se incorporan años más recientes al periodo objeto de estudio (Sardá, 2014; Schneider, 2015).

Figura 2. Proporción estimada de la economía informal sobre la economía oficial en España

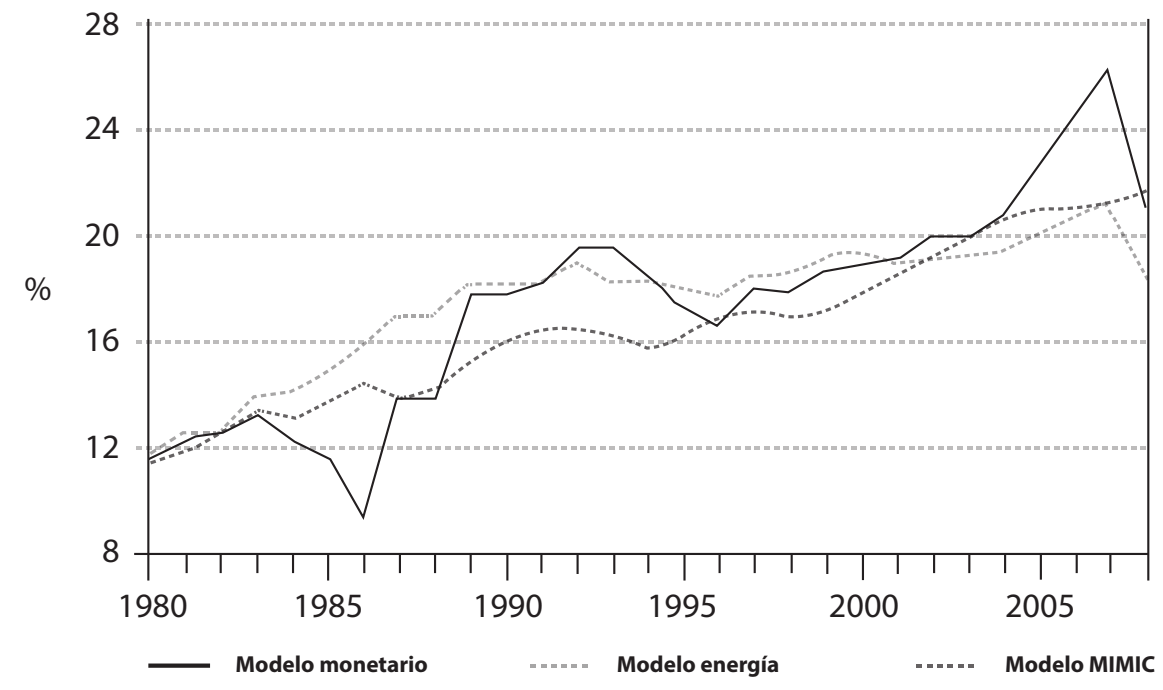

Fuente. Arrazola et al. (2011). 
Como de forma muy acertada concluye este estudio, los resultados obtenidos no son sorprendentes si tenemos en cuenta que en España parece existir una cierta tolerancia hacia la existencia de actividades informales. Sin embargo, no se debe caer en la tentación de considerar la economía informal como una parte consustancial de nuestra vida económica. La economía informal es considerada por algunos como una válvula de escape en situaciones de recesión como las actuales, pero, por la multiplicidad de distorsiones que genera -problemas de equidad, eficiencia, distorsión de la competencia, etc.-, la economía informal supone a largo plazo un duro lastre para la economía española (Arrazola et al., 2011).
Pero ¿es la situación de la economía española diferente de la de otros países de nuestro entorno o similares en tamaño de PIB? Veamos algunos datos en este sentido.

Más adelante se muestra que, comparándonos con países relativamente más próximos a nosotros, España presenta una tasa de economía informal de las más elevadas. Si acotamos más la comparación a países más cercanos, solo Italia, Portugal y Grecia presentan porcentajes superiores al español, pero quedamos muy lejos de países como Alemania, Francia y el Reino Unido (Figura 3).

Figura 3. Tamaño de la economía informal en algunos países (OCDE, 2012)

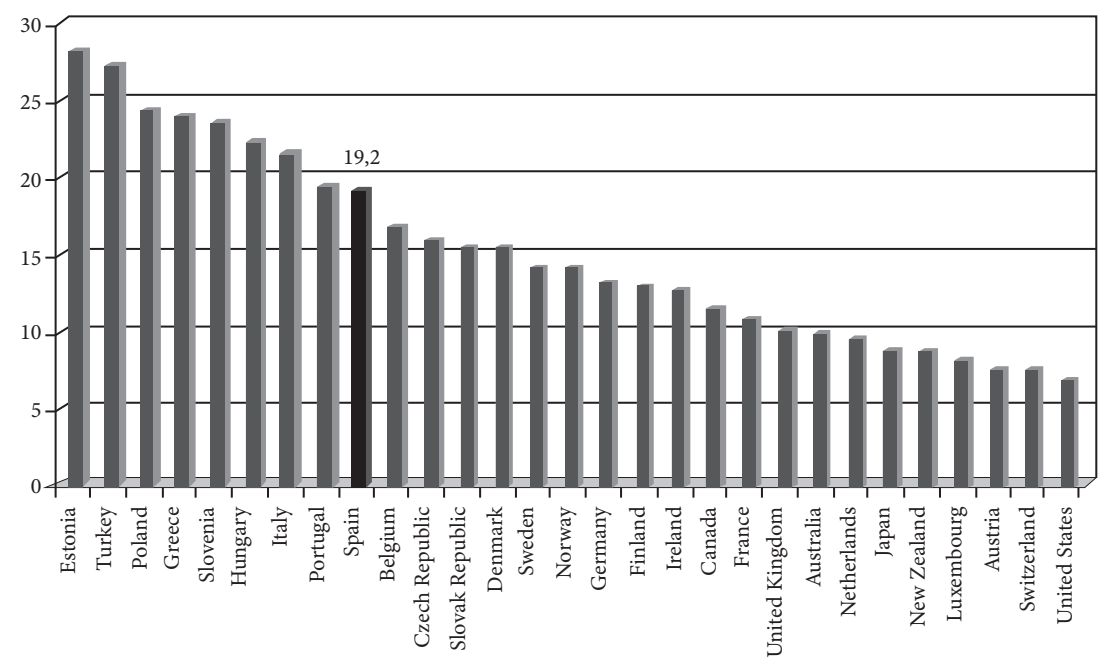

Fuente. Schneider (2015).

$\mathrm{Si}$ analizamos la relación existente entre el tamaño de economía informal de estos países y diferentes variables que a priori parecen estar relacionadas con la economía informal, se puede comprobar si dicha relación realmente existe.

Si se consideran los impuestos totales con respecto al PIB -en porcentaje-, la impor- tancia de los impuestos directos dentro de la recaudación total y la importancia de los impuestos indirectos también dentro de la recaudación total de impuestos, en principio deberíamos esperar que aquellos países que presenten una mayor presión fiscal debieran ser los que tendrían un mayor incentivo a participar en la economía informal. Lo mismo debería ocurrir con los impuestos directos 
sobre el total de recaudación impositiva, pero respecto de la recaudación de impuestos indirectos sobre el total recaudado parece razonable esperar que cuanto mayor sea dicha proporción menor debería ser el volumen de economía informal.

Por su parte, del trabajo realizado por Sardá (2014), se concluye que los países más desarrollados son los que presentan mayores tasas de presión fiscal, sin embargo, presentan tamaños de economía informal bajos o relativamente moderados. Al contrario, los países menos desarrollados de la OCDE tienen altos niveles de economía informal $y$, en general, presiones fiscales menores de las de los países más desarrollados. España se encuentra en una posición intermedia, aunque más cercana a los países menos desarrollados dentro de la OCDE.
Considerando variables referidas al mercado de trabajo, se cumple que, a mayor tamaño de economía informal, mayor tasa de paro -o de porcentaje de autónomos-. Cuando las variables observadas se refieren al bienestar -índice de desarrollo humano, (IDH)-, transparencia de los países, que está fuertemente relacionada con la corrupción, y a su nivel educativo -porcentaje de estudiantes que ha superado estudios secundarios-, se cumple que a mayor nivel de desarrollo humano, menor nivel de economía informal; y a mayor transparencia, también menor volumen de economía informal. La relación entre el nivel de enseñanza y el tamaño de economía informal ya no está tan clara (Sardá, 2014).

En todos los casos, España ocupa una posición intermedia, pero más próxima a la de los países menos desarrollados.

\section{Economía informal y emprendimiento}

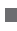

$\mathrm{L}$ os economistas siempre hemos estado interesados en la economía informal, tal y como se ha definido dados los objetivos de las presentes líneas. Ese interés se ha fundamentado en intentar dar respuestas a una serie de importantes cuestiones: ¿cuáles son las causas de la economía informal? ¿Cuál es su tamaño y extensión? ¿Qué implicaciones tiene para la propuesta de políticas públicas? ¿Qué recomendaciones en este sentido podemos aportar los economistas? ¿Cuáles son las soluciones para la economía informal?

En este apartado, pretendemos realizar y responder una cuestión adicional, ofreciendo un enfoque nuevo: ¿cuáles son las características de la empresas -españolas- que desarrollan su labor en la economía informal y cuáles son las repercusiones de su existencia en la capacidad de creación de empresas en nuestro país?

Lo primero que debemos hacer es identificar las características del emprendedor informal, en lo que se refiere a si existen focos localizados que fomenten esta actuación:

- Se agrupan en poblaciones de bajos ingresos (Van Beukering, 1994; Galemba, 2008; Holley, 1993). Aunque investigaciones empíricas (Williams, 2009) han señalado que los emprendedores informales no son solo de ingresos bajos, sino que se sitúan en ambos extremos de lo que llamaríamos escala salarial: los que 
ganan poco y los que ganan mucho son más propensos a emprender en la sombra. La diferencia entre ellos es que aquellos con menores ingresos se mantienen completamente al margen de la economía formal, mientras que los más acaudalados lo hacen fuera de la formalidad solo parte de su actividad empresarial.

- Se concentran en poblaciones marginadas del mercado laboral (Evans, Syrett y Williams, 2006; Katungi, Neale y Barbour, 2006; Llanes y Barbour, 2007). $\mathrm{Si}$ bien es verdad que en tales casos estos emprendedores informales no tienen un empleo oficial, no significa que los emprendedores informales se encuentren desempleados. De hecho, algunos estudios demuestran que una vez puesta en marcha su aventura empresarial de manera informal, como alternativa mucho menos arriesgada, abandonan su empleo, formal o informal, solo cuando comprueban la viabilidad de su negocio (Guariglia y Kim, 2006; McCormick, 1998; Reynolds, Bygrave, Autio y Hay, 2002).

En cualquier caso, estas características varían bastante geograficamente, por lo cual hay que tomarlas con cautela sin poder hacer generalizaciones.

Si nos centramos en identificar las motivaciones del emprendedor, partiendo primero de la sencilla clasificación que distingue entre emprendedores por necesidad -los que crean su propio negocio ante la falta de otras oportunidades o alternativas- $y$ los emprendedores por oportunidad -los que intentan aprovechar una demanda insatisfecha en el mercado o quieren ser su propio jefe-, nos servirá para enfocarnos en las motivaciones del emprendedor informal.
En la mayoría de las ocasiones se presenta al emprendedor informal como de necesidad: no tiene otra alternativa que ocupar la informalidad como modo de sobrevivir (Boyle, 1994; Hughes, 2006; Singh y DeNoble, 2003). Sin embargo, muchos autores convienen en argumentar lo contrario: los emprendedores deciden participar voluntariamente en la economía informal, porque encuentran en ella más autonomía, flexibilidad y libertad que en la alternativa contraria (Cross, 1997; Gerxhani, 2004; Snyder, 2004). En este último sentido, parecería que los estudios se contradicen, en el sentido de que, si se emplea la misma clasificación de los emprendedores, formales e informales, se está distinguiendo entre de necesidad y de oportunidad. Si el informal elige ese sector, ya no será por necesidad, en tanto en cuanto está haciendo una elección.

Uno de los costes económicos de la economía informal sería una mala asignación de la capacidad de emprendimiento de la sociedad (Lemieux, 2007). La economía informal para los emprendedores es una alternativa a unas políticas públicas pobres y la intensidad regulatoria asociada a crear y mantener un nuevo negocio (La Pira y Zhao, 2011).

La canalización del emprendimiento hacia actividades menos productivas para la sociedad en su conjunto e incluso totalmente improductivas, es otro impacto, menos visible, de las políticas públicas dirigidas a limitar o restringir los intercambios entre los diferentes agentes económicos mediante mercados abiertos, menos regulados. Una parte de la teoría económica argumenta que cuando el emprendimiento en actividades formales no tiene recompensa o incluso es castigado, esos emprendedores tienden a asignar su tiempo y esfuerzo a actividades informales. Por ejemplo, el aluvión

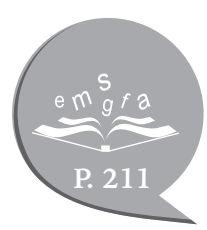


de invenciones en China a principios del segundo milenio -ruedas hidráulicas, papel, la pólvora, tal vez la brújula- proporciona un ejemplo típico: estos inventos no condujeron al desarrollo económico porque la gente con espíritu emprendedor solo fue recompensada siendo incluida en las filas de la poderosa burocracia estatal (Baumol, 1996, pp. 36-37). De manera más general, podríamos afirmar que una consecuencia de las políticas públicas que conllevan obstáculos al libre intercambio mediante el mecanismo del mercado sería desviar las actividades empresariales a los mercados subterráneos, la economía informal, y en algunos casos, a la delincuencia. Este aspecto de la mala asignación de los recursos empresariales causados por los impedimentos para el intercambio se olvida fácilmente (Lemieux, 2007).

En similar sentido podríamos afirmar que la reasignación de recursos hacia la economía informal daña enormemente a los competidores; por ejemplo, emprendedores legales que son víctimas de la competencia desleal (Lemieux, 2007).

En definitiva, una mala asignación productiva hacia la economía informal desvía algunos talentos de emprendedores fuera de la economía legal a actividades ilegales.
Estos empresarios a menudo tienen menos oportunidad de beneficiar al consumidor de lo que tendrían si pudieran ejercer sus ideas abiertamente en el mercado. Del mismo modo, se producen distorsiones y costes cuando los recursos se desvían a algunos sectores u ocupaciones simplemente para facilitar la evasión o elusión fiscal.

Los empresarios pueden llegar a ser más eficientes en la evasión o elusión fiscal por una mala regulación que en satisfacer de forma adecuada la demanda del consumidor. Es fundamental ver cómo este coste de la economía informal es, de hecho, un coste de las políticas públicas que la generaron (Lemieux, 2007).

Existen también estudios que ilustran el llamado círculo vicioso por el que se relacionan las políticas públicas y el crecimiento de la inmigración ilegal con la aparición de más emprendedores en la economía informal y su relación con la corrupción que fomenta esa informalidad en los nuevos negocios. La Pira y Zhao (2011), por ejemplo, identifican dicho círculo vicioso en las economías griega e italiana. Por tanto, el entorno político, social y cultural aboca, en gran medida, a los emprendedores a la economía informal. 


\section{Metodología de la investigación}

\subsection{Datos}

Se utiliza la base de datos del Global Entrepreneurship Monitor (GEM), que es un observatorio de la actividad emprendedora en el que participan regularmente más de noventa países y que tiene carácter anual (Informe GEM España 2012).

El GEM inició su desarrollo en 1999, y España se incorporó un año más tarde. La metodología empleada es la misma para cada una de las naciones y los territorios participantes. Según el Informe GEM España 2010: «La clave de esta metodología es la homogeneidad de las herramientas empleadas para recoger la información» (p. 10). Esto permite no solo realizar comparaciones fiables entre países y regiones, sino también para una misma nación en diferentes momentos.

Así mismo, esta base de datos ofrece una información muy variada referida al emprendimiento, el intraemprendimiento, empresas jóvenes, compañías consolidadas y autónomos, entre otros aspectos. Pero también se puede extraer una información muy rica en relación con una serie de variables sociodemográficas y económicas que permiten extender el análisis más allá del emprendimiento, como es el caso de la economía informal. Este tema se trató de forma monográfica en 2012 por el GEM en los países participantes.

\subsection{Muestra}

Se utiliza el Informe GEM España 2012. La encuesta por muestreo «es un método directo que permite conocer algunas características relevantes de los agentes que intervienen en la economía informal, si bien no resulta difícil comprender sus limitaciones» (Arrazola el al., 2011, p. 19), principalmente si el objetivo es cuantificar el volumen de fraude.

Aunque no es difícil imaginar sesgos en las respuestas, el método proporciona datos valiosos a esta investigación para identificar factores económicos y socioculturales que impulsan o favorecen la economía informal, expresada respecto de las empresas que dan de alta o no su actividad en el registro civil de sociedades.

La muestra está conformada por un total de 21900 observaciones. Tras una adecuada exploración y depuración de datos, se trabaja con una submuestra de tamaño 2991. La condición aplicada para determinar el tamaño de esta es que la observación sea una empresa naciente, nueva o consolidada.

\subsection{Variables}

- Variable dependiente: registrada $-0=$ No; 1 = Sí-. Cuando la variable adopta el valor 0, la empresa -emprendedor- no se encuentra inscrita en el Registro Civil de Sociedades y, por tanto, opera informalmente. Cuando la variable toma el valor 1 significa que la empresa está registrada, por lo cual ejerce su actividad dentro de la economía formal.

- Variables independientes: las variables utilizadas provienen de la revisión de la literatura realizada, pero también de las posibilidades de segmentación que proporciona la base de datos GEM. Las variables empleadas son motivación del 
emprendedor, fase de actividad, nacionalidad, género, edad, nivel de formación, sector de actividad en el que opera, renta del hogar al que pertenece el emprendedor y la región española donde radica su actividad:

* Motivación: esta variable toma el valor 0 cuando el emprendedor ha creado la empresa por necesidad, y el valor 1 cuando la ha constituido por oportunidad.

* Fase: esta variable toma el valor 1 cuando la empresa lleva en el mercado entre 0 y 3 meses: empresa naciente; el valor 2 cuando la empresa tiene entre 3 y 42 meses: nueva; y el valor 3 cuando la antigüedad de la compañía supera los 42 meses de actividad: empresa consolidada.

* Nacionalidad: si la variable toma el valor 0, el emprendedor es español, mientras que, si es 1 , es extranjero.

* Género: cuando la variable adopta el valor 0, el emprendedor es un hombre, y cuando es 1 , se trata de una mujer.

* Edad: si la variable vale 0 el emprendedor tiene entre 18 y 41 años, y 1 cuando supera los 42 .

* Formación universitaria: esta variable toma el valor 0 si el emprendedor no tiene formación universitaria, y 1 si este es universitario.

* Servicios: esta variable toma el valor 0 si la empresa no pertenece al sector servicios, o sea, es parte, siguiendo la nomenclatura GEM, del sector extractivo e industria; y toma el valor 1 si la empresa pertenece al sector servicios, ya sea su cliente otra empresa, ya sea un consumidor final.
* Renta del hogar: la variable toma el valor 0 cuando el emprendedor vive en un hogar cuya renta total es igual o inferior a EUR 30000 anuales, y el valor 1 cuando supera dicha cifra.

* Comunidad autónoma: tanto en el caso del análisis descriptivo como en el del logit se ha utilizado el criterio específico de Serrano Sanz (2010), cuyo trabajo identifica como comunidades autónomas (CCAA) con menores niveles de economía informal a Aragón, Asturias, Cantabria, Navarray País Vasco. Regiones a las que hemos denominado CCAA limpias. De este modo, cuando el valor de la variable adopta el valor 0 , la comunidad autónoma es considerada no limpia, y cuando adopta el valor 1 , se considera limpia -con bajo nivel de economía informal-.

\subsection{Técnicas}

En primer lugar, se realiza un análisis descriptivo basado principalmente en el cálculo de frecuencias y porcentajes de las variables. Tratamiento apropiado para variables que vienen expresadas en escalas nominal y ordinal. Así mismo, se utilizan tablas de contingencia y de correlación para el análisis conjunto de variables.

Todos los análisis descriptivos de la muestra se dotan de significancia estadística utilizando los correspondientes test de hipótesis: independencia, correlación y diferencia de medias.

Por último, se utiliza el modelo de probabilidad lineal logit para determinar qué factores y cómo influyen estos en el desarrollo de una actividad económica que opera informalmente. La selección de esta técnica se basa principalmente en que la variable dependiente utilizada es dicotómica $(0 / 1)$, pero también porque 
permite identificar cuál de las variables explicativas ejerce una mayor influencia sobre la variable explicada.

Esta técnica es ampliamente utilizada en el campo del emprendimiento. Algunos ejemplos pueden encontrarse en Fernández y Nieto (2005), quienes afirman que

los modelos de elección binaria son análisis que podrían asimilarse a los métodos de regresión en los que, por la naturaleza de los datos, se necesita un trato especial de los mismos. [...] Los coeficientes de las variables independientes muestran el impacto de los cambios en las variables sobre la probabilidad de ocurrencia de la variable dependiente (p. 118).

Según Ramos (s. f.), para predecir una variable dicotómica, que adopta valores 0 o 1 , su relación con los predictores es no lineal. Lo que se predice no es directamente la variable sino la probabilidad de que la variable adopte un cierto valor, por ejemplo, la probabilidad de que la empresa se inscriba en el Registro Civil (p).

Para predecir una probabilidad pueden utilizarse diferentes funciones, entre las que se destaca la logística:

$$
P=\frac{e^{u}}{\left(1+e^{u}\right)}
$$

Donde el modelo lineal aparece realmente en el exponente:

$$
u=a+b_{1} X_{1}+b_{2} X_{2}+\ldots+b_{p} X_{p}
$$

De este modo, la expresión (3) es conocida como logit o logaritmo de las verosimilitudes:

$\ln \left(\frac{p}{1-p}\right)=u=a+b_{1} x_{1}+b_{2} x_{2}+++b_{p} x_{p}$

\section{Caracterización de la empresa española que ejerce su actividad en la economía informal}

\subsection{Características del emprendedor que opera en la economía informal}

De un primer análisis descriptivo se obtiene una aproximación de las características del emprendedor de la muestra en relación con su predisposición a operar o no en la informalidad.

Se observa que el $21.1 \%$ de los emprendedores por necesidad no registran su actividad (Figura 4). Este porcentaje es ligeramente superior a las actividades no registradas en el caso de emprendimiento por oportunidad $(15.3 \%)$.

En la misma representación, se observan otras características del emprendedor que desarrolla actividades dentro de la informalidad. En este sentido, según los resultados de la muestra, las características de este tipo de emprendedor se podrían concretar en que se encuentran en su primera fase de actividad $-58.1 \%$ no se registra-; que es extranjero $-24.7 \%$ de los emprendedores extranjeros no dan de alta sus actividades 
económicas-; con una edad inferior a 42 años -23.9 \% no registra-; universitarios -19 \%-; del sector servicios -16.4\%-; y con unos ingresos totales del hogar entre 20000 y 60000 euros anuales $-65 \%$-.

Figura 4. Análisis descriptivo de las características de las empresas informales
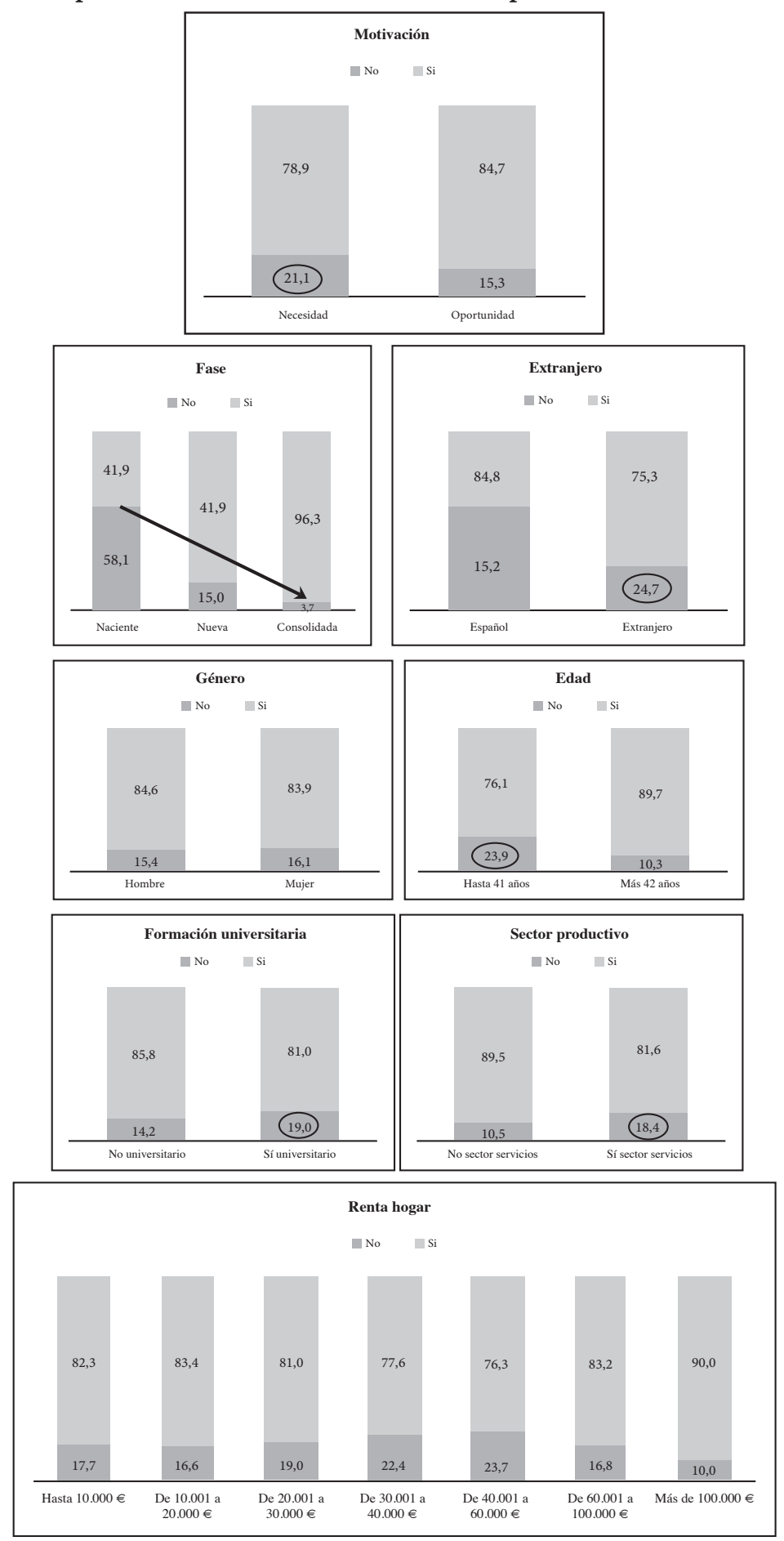

Fuente. Elaboración propia a partir de GEM (2012). 
Nota 1: «Sí», la empresa sí se encuentra inscrita en el Registro Civil de Sociedades, y por consiguiente, no opera informalmente; «No», la empresa no se encuentra inscrita en el Registro Civil de Sociedades, y por tanto, opera informalmente.

Nota 2: Existe dependencia entre la variable «registrada» y las características variables independientes- del emprendedor español, según el test de independencia de la chi-cuadrado (véase anexo1).

Figura 5. CCAA y economía informal
Al realizar el estudio por CCAA, se desprende que en las regiones con menores niveles de economía informal, según Serrano Sanz (2010), son donde mayor porcentaje de empresas registradas hay y, por ende, donde existe un mayor nivel de transparencia en relación con el resto de CCAA (Figura 5).

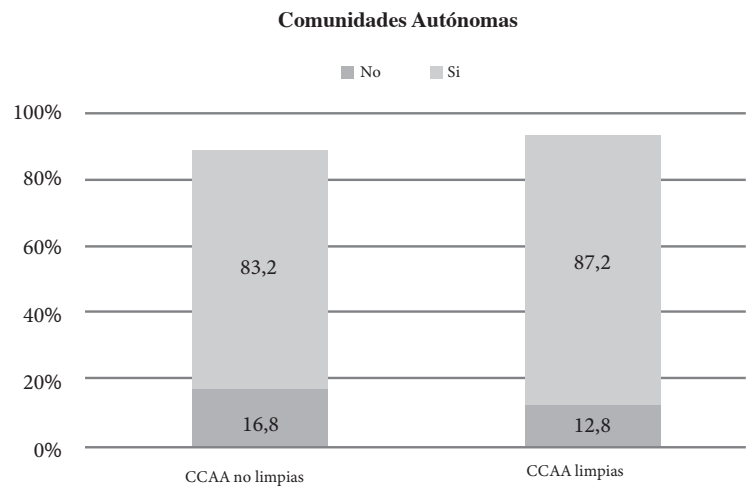

Fuente. Elaboración propia a partir de GEM (2012).

Nota: Existe dependencia entre la variable «registrada» y la variable independiente CCAA limpia según el test de independencia de la chi-cuadrado (Anexo1).

Todas las características del emprendedor estudiadas -motivación, fase de actividad, nacionalidad, edad, formación, sector, renta y zona geográfica-, salvo el género, tienen algún tipo de relación estadísticamente significativa con la predisposición o no a desarrollar actividades no inscritas en el Registro Civil de Sociedades.

\subsection{Impacto de las características del emprendedor en la economía informal}

Para llevar a cabo este apartado, se han recodificado algunas variables con el objetivo de que puedan cumplir los requisitos del análisis logit empleado. La recodificación se ha realizado atendiendo a los resultados obtenidos en el análisis descriptivo previo, excepto en las CCAA, en el que se ha seguido el criterio de Serrano Sanz (2010). 
De este modo, la variable dependiente es registrada $(0=$ No; $1=$ Sí $)$ y las independientes son motivación $(0=$ necesidad; $1=$ oportunidad $)$, naciente $(0=$ nueva $\mathrm{o}$ consolidada; 1 = naciente), nacionalidad $(0=$ española; $1=$ extranjero $)$, género $(0$ $=$ hombre; $1=$ mujer), educación superior $(0=$ no; $1=$ sí $)$, sector servicios $(0=$ otro sector; 1 = sector servicios), edad corte 42 $(0=18-41$ años; $1=42-65$ años $)$, renta corte EUR 30.000 (0 = renta hogar anual hasta EUR 30000 inclusive; 1 = renta hogar anual más de EUR 30 001), CCAA limpias $(0=$ resto de CCAA; 1 = Aragón, Asturias, Cantabria, Navarra y País Vasco).

Nótese también que el propósito de este modelo de regresión logística no es predecir sino identificar el sentido y la intensidad de las relaciones causales entre las variables independientes y la dependiente, de tal forma que se puedan detectar las características de la empresa y del emprendedor que verdaderamente influyen en la economía informal.

Los resultados de la regresión muestran que el ajuste global del modelo es satisfactorio, atendiendo al test de Hosmer and Lemeshow -la hipótesis nula indica que la matriz de datos pronosticada es similar a la matriz de datos observada-. Así mismo, las características identificadas como influyentes en la actividad informal de la empresa cumplen el criterio del nivel de significación inferior al $5 \%$.

Del análisis descriptivo realizado, se deducía un primer perfil de empresa/ emprendedor informal en España:

- Emprendimiento por necesidad.

- Empresa naciente -primera fase de actividad-.

- Nacionalidad extranjera.

- Menores de 42 años.
- Con formación universitaria.

- Perteneciente al sector servicios,

- De renta media baja.

- Residente en CCAA distintas de Aragón, Asturias, Cantabria, Navarra y País Vasco.

Sin embargo, el análisis logit realizado muestra que al incluir todas las variables simultáneamente en el estudio, unas arrastran a otras por importancia en su efecto sobre la economía informal. Así, que la empresa sea naciente, que se emprenda por razones de necesidad, que la compañía ejerza su actividad en el sector servicios, que la edad del emprendedor no supere los 42 años y que la renta del hogar de dicho emprendedor sea mayor de EUR 30000 continúan siendo características determinantes e influyentes en la economía informal representada por el registro empresarial (Tabla 2A). Sin embargo, ni la nacionalidad, ni el género, ni el nivel de formación ni el tipo de CCAA parece que influyen significativamente en que las empresas registren o no su actividad.

De estas cuatro variables explicativas que son significativas -test de Wald-, hay una de ellas que ejerce una influencia especialmente importante en la economía informal: la fase de actividad en la que se encuentra la empresa. Así, en el caso de empresas nuevas o consolidadas, es menos frecuente encontrarse con situaciones irregulares; mientras que cuando la antigüedad de la empresa no supera los tres meses, se disparan los casos de actividades no registradas. Y es lógico porque en la primera fase de actividad empresarial muchas compañías aún no han concluido totalmente los procesos de inscripción en los registros cuando ya han iniciado su actividad empresarial. 
Por este motivo o efecto arrastre de esta variable sobre las demás, se ha decidido replicar el análisis logit eliminando la fase de actividad de la empresa. Los resultados mejoran para otras variables que antes se veían afectadas por la corta edad de la compañía. En la nueva regresión, al $90 \%$ de nivel de confianza, las variables independientes que antes eran estadísticamente influyentes en la economía informal siguen siéndolo ahora, pero además se añade el efecto de la nacionalidad y de la comunidad autónoma. Concretamente, cuando el emprendedor es extranjero existe una mayor probabilidad de que su empresa no se registre en comparación con los emprendedores de nacionalidad española; del mismo modo que en las CCAA con menos actividad informal (Aragón, Asturias, Cantabria, Navarra y País Vasco), las empresas tienden a registrar su actividad con mayor frecuencia que en el resto de regiones (Tabla 2B). Resultados que en el primer logit no eran significativos -ni al $90 \%$ de confianza- por el arrastre de la fase de actividad.

Finalmente, se detecta que ni el género ni el nivel de formación del emprendedor influyen en que la actividad de la empresa sea registrada. No son estadísticamente significativos en ninguna de las dos regresiones logísticas realizadas.

Tabla 2. Análisis de regresión logit

(A) Todas las variables

\begin{tabular}{|c|c|c|c|c|c|c|}
\hline & B & S.E. & Wald & df & Sig. & $\operatorname{Exp}(B)$ \\
\hline Motivación & 0.816 & 0.168 & 23.542 & 1 & $0.000 * * *$ & 2.262 \\
\hline Naciente & -2.926 & 0.156 & 350.017 & 1 & $0.000 * * *$ & 0.054 \\
\hline Nacionalidad & -0.297 & 0.282 & 1.111 & 1 & 0.292 & 0.743 \\
\hline Género & 0.058 & 0.164 & 0.126 & 1 & 0.722 & 1.060 \\
\hline Educación superior & 0.132 & 0.167 & 0.626 & 1 & 0.429 & 1.142 \\
\hline Sector servicios & -0.384 & 0.186 & 4.253 & 1 & $0.039^{* *}$ & 0.681 \\
\hline Edad corte 42 & 0.789 & 0.152 & 26.863 & 1 & $0.000^{* * *}$ & 2.201 \\
\hline Renta2tramos_30.000 & -0.514 & 0.165 & 9.691 & 1 & $0.002^{* * *}$ & 0.598 \\
\hline 0. & 0. & 0.176 & 0.101 & 1 & 0.750 & 1.058 \\
\hline Constante & 1.921 & 0.223 & 74.242 & 1 & $0.000 * * *$ & 6.831 \\
\hline \multicolumn{7}{|c|}{$\begin{array}{l}\text { a. Variable(s) introducida(s) en el paso } 1 \text { : motivación, naciente, nacionalidad, género, educación } \\
\text { superior, sector servicios, edad corte } 42 \text {, renta corte EUR } 30000 \text { y CCAA limpias. } \\
\text { b. Test de Hosmer and Lemeshow: p-valor }=0.303 \text { (véase anexo } 2 \text { ). } \\
\left.\text { c. }\left({ }^{* * *}\right) \text { p-valor }<0.01 ;{ }^{* *}\right) \text { p-valor }<0.05 \text {. }\end{array}$} \\
\hline
\end{tabular}


(B) Todas las variables excepto la fase de actividad

\begin{tabular}{|c|c|c|c|c|c|c|}
\hline & B & S.E. & Wald & $\mathrm{df}$ & Sig. & $\operatorname{Exp}(B)$ \\
\hline Motivación & 0.563 & 0.139 & 16.498 & 1 & $0.000^{* * *}$ & 1.756 \\
\hline Nacionalidad & -0.500 & 0.233 & 4.603 & 1 & $0.032 * *$ & 0.607 \\
\hline Género & 0.053 & 0.137 & 0.152 & 1 & 0.696 & 10.055 \\
\hline Educación superior & 0.038 & 0.140 & 0.073 & 1 & 0.787 & 1.039 \\
\hline Sector servicios & -0.683 & 0.158 & 18.694 & 1 & $0.000^{* * *}$ & 0.505 \\
\hline Edad corte 42 & 0.965 & 0.128 & 56.838 & 1 & $0.000^{* * *}$ & 2.625 \\
\hline Renta2tramos 30.000 & -0.226 & 0.136 & 2.755 & 1 & $0.097^{*}$ & 0.798 \\
\hline CCAA limpias & 0.272 & 0.149 & 3.351 & 1 & $0.067^{*}$ & 1.313 \\
\hline Constante & 1.044 & 0.181 & 33.234 & 1 & $0.000^{* * *}$ & 2.842 \\
\hline \multicolumn{7}{|c|}{$\begin{array}{l}\text { a. Variable(s) introducida(s) en el paso 1: motivación, nacionalidad, género, educación superio } \\
\text { sector servicios, edad corte } 42 \text {, renta corte EUR } 30000 \text { y CCAA limpias. } \\
\text { b. Test de Hosmer and Lemeshow: p-valor }=0.956 \text {. Mejora el ajuste global. (véase anexo } 3 \text { ). } \\
\text { c. }\left({ }^{* *}\right) \text { p-valor }<0.01 ;\left({ }^{* *}\right) \text { p-valor }<0.05 ;\left({ }^{*}\right) \text { p-valor }<0.10 \text {. }\end{array}$} \\
\hline
\end{tabular}

Fuente. Elaboración propia a partir de GEM (2012).

\section{Conclusiones y limitaciones}

$\mathbf{E}_{\mathrm{y}}^{1}$ lobjetivo de este trabajo ha sido describir y analizar el perfil de las empresas españolas -emprendedores españoles- que ejercen su actividad dentro de la economía informal, utilizando el método directo de la encuesta proveniente de la citada base de datos GEM.

Derivado de la explotación de los datos de GEM se extraen algunas conclusiones de las características de las empresas/emprendedores españoles que operan en la informalidad -por orden de importancia-:

- Las empresas que operan en la economía informal suelen encontrarse en una primera fase de actividad, normalmente menos de tres meses. Son las llamadas empresas nacientes, siguiendo la nomenclatura GEM. Es la variable con mayor capacidad explicativa del primer modelo construido. De hecho, cuando se elimina del segundo modelo, para ver el efecto arrastre en las demás variables independientes, se observa que las variables CCAA limpias y nacionalidad son variables explicativas del fenómeno de informalidad -test de Wald-. Este efecto indica que hubo un importante emprendimiento extranjero, cuya actividad se desarrolló principalmente en CCAA no limpias:

- Suelen ser empresas constituidas por necesidad, que presentan un comportamiento reactivo.

- El emprendedor suele tener menos de 42 años.

- La compañía normalmente opera en el sector servicios. 
- Los emprendedores extranjeros presentan una mayor tasa de no registros que los españoles, aunque este efecto se disipa en cuanto se tiene en cuenta la antigüedad de la empresa, que es la variable con mayor capacidad explicativa de la inscripción de una compañía en el Registro Civil de Sociedades.

- Las empresas constituidas en Aragón, Asturias, Cantabria, Navarra y País Vasco -comunidades llamadas limpias- tienden a registrarse con más probabilidad que las sociedades de otras regiones. Este efecto nuevamente desaparece cuando se considera la fase de actividad en la que se encuentra la compañía por el efecto arrastre de esta variable.

- Los emprendedores que viven en hogares con rentas superiores a los EUR 30.000 presentan porcentajes de no registros mayores que los más desfavorecidos.

- Finalmente, ni el género ni la educación universitaria influyen en que haya más probabilidad de que las empresas no se registren. No obstante, en el caso de la formación, al observar la matriz de correlaciones de las variables explicativas, se aprecia una elevada asociación entre las variables educación universitaria y renta del hogar, así como entre educación universitaria y motivación para emprender, ambas positivas $\mathrm{y}$ estadísticamente significativas, lo cual podría justificar que los emprendedores con estudios universitarios no presenten mejores resultados que los que no los tienen puesto que se produce un efecto de solapamiento -o arrastreque deja sin significatividad al nivel de formación -recuérdese que en el análisis descriptivo, la formación universitaria sí presentaba dependencia con el registro de la actividad de las empresas-.

En la variable género del emprendedor, se contrasta a través del modelo logit lo que se intuía en el análisis descriptivo: no hay efecto explicativo. No obstante, se ha considerado pertinente incluir esta variable en el análisis conjunto por si aparecían interacciones entre variables que incrementarán su poder explicativo.

Por último, es importante tener en cuenta que los resultados aquí descritos pudieran presentar algunas limitaciones. La primera de ellas se relacionaría con una posible laguna de características que podrían explicar el no registro de las empresas. Sin embargo, la base de datos GEM no ofrece muchas más posibilidades que las que en este trabajo se utilizan. En segundo lugar, el análisis realizado se lleva a cabo a partir de los datos de 2012, por lo cual podrían haberse producido algunos ligeros cambios en los perfiles de las empresas informales en los últimos años, no contemplados en esta investigación. Y tercero, la variable fase de actividad podría incorporar un sesgo vinculado a la etapa de inicio de la empresa en la que ya presenta actividad económica pero todavía no ha sido registrada formalmente por una cuestión de tiempo, no de intención.

En cualquier caso, la identificación de las características tipo que explican el comportamiento de las empresas a la hora de registrar o no su actividad indudablemente aporta valor para el diseño y la implementación de la política económica que permita monitorizar y perseguir con mayor precisión los casos de actividades no computadas por el fisco. Así mismo, las limitaciones identificadas abren unas líneas de investigación futuras que podrían detallar aún más los resultados aquí obtenidos. 


\section{Referencias}

Arrazola, M., Hevia, J. de, Mauleón, I. y Sánchez, R. (2011). La economía sumergida en España. En Arrazola, M., Hevia, J. de, Mauleón, I., Sánchez, R., Malo, M. Á., Garrido, L. y Cueto, B., Dos ensayos de actualidad sobre la economía española (pp. 13-78). Madrid: Funcas. Recuperado de http://www.funcas. es/publicaciones/Sumario.aspx? IdRef = 9-08005

Bajada, C. y Schneider, F. (2005). Size, causes and consequences of the undergroundeconomy: An international perspective. Aldershot, Reino Unido: Ashgate Publishing Company.

Baumol, W. J. (1996). Entrepreneurship: Productive, unproductive, and destructive. Journal of Business Venturing, 11(1), 3-22.

Beukering, P. van (1994). An economic analysis of different types of formal and informal entrepreneurs, recovering urban solid waste in Bangalore (India). Resources, Conservation and Recycling, 12(3-4), 229252.

Boyle, E. (1994). The rise of the reluctant entrepreneurs. International Small Business Journal, 12(2), 63-69.

Círculo de Empresarios (2010). Implicaciones de la economía sumergida en España. Madrid: Círculo de Empresarios.

Cross, J. C. (1997). Entrepreneurship \& exploitation: Measuring independence and dependence in the informal economy. International Journal of Sociology and Social Policy, 17(3/4), 37-62.

Evans, M., Syrett, S. y Williams, C. C. (2006). The informal economy and deprived neighbourhoods: A systematic review. Londres: Department of Local Government and Regions.

Feld, L. P. y Schneider, F. (2010). Survey on the shadow economy and undeclared earnings in OECD countries. German Economic Review, 11(2), 109-149.

Fernández, Z. y Nieto, M. J. (2005). La estrategia de internacionalización de la pequeña empresa familiar. Cuadernos de Economía y Dirección de la Empresa, 22, 107-125.
Friedman, E., Johnson, S., Kaufmann, D. y ZoidoLobaton, P. (2000). Dodging the grabbing hand: The determinants of unofficial activity in 69 countries. Journal of Public Economics, 76(3), 459-493.

Galemba, R. B. (2008). Informal and illicit entrepreneurs: Fighting for a place in the neoliberal economic order. Anthropology of Work Review, 29(2), 19-25.

Gerxhani, K. (2004). The informal sector in developed and less developed countries: A literature survey. Public Choice, 120(3-4), 267-300.

Global Entrepreneurship Monitor (2010). Informe GEM España. Recuperado de http://www.gem-spain. com/wp-content/uploads/2015/03/Informes\%20 antiguos/GEM2010.pdf

Global Entrepreneurship Monitor (2012). Informe GEM España. Recuperado de http://www.gem-spain. com/wp-content/uploads/2015/03/Informes $\% 20$ 2012/GEM2012.pdf

Guariglia, A. y Kim, B. Y. (2006). The dynamics of moonlighting in Russia. Economics of Transition, 14(1), 1-45.

Hart, K. (1973). Informal income opportunities and urban employment in Ghana. The Journal of Modern African Studies, 11(1), 61-89.

Holley, H. (1995). Limits to and development strategies for the informal sector. A case study about informal woodworking entrepreneurs in Trujillo/ Peru. International Journal of Sociology And Social Policy, 15(8/9/10), 283-294.

Hughes, K. D. (2006). Exploring motivation and success among Canadian women entrepreneurs. Journal of Small Business \& Entrepreneurship, 19(2), 107-120.

Johnson, S., Kaufmann, D. y Zoido-Lobatón, P. (1998). Corruption, public finances and the unofficial economy. Washington, DC: The World Bank, Discussion Paper. 
Katungi, D, Neale, E. y Barbour, A. (2006). People in low-paid informal work: Need not greed. York: Joseph Rowntree Foundation.

La Pira, F. y Zhao, W. (2011). Entrepreneurship and the shadow economies of southern Europe: A vicious circle perspective. Ponencia presentada en EURAM 2012 Conference, Rotterdam, Rotterdam School of Management, Erasmus University.

Lafuente Felez, A. (1980). Una medición de la economía oculta en España. Boletín de Estudios Económicos, 111, 581-593.

Lemieux, P. (2007). The underground economy: Causes, extent, approaches. Montreal: Montreal Economic Institute.

Llanes, M. y Barbour, A. (2007). Self-employed and microentrepreneurs: Informal trading and the journey towards formalisation. Londres: Community Links.

McCormick, D. (1998). Fundis and formality: Very small manufacturers in Nairobi. En M. Schatzberg (ed.), The political economy of Kenya (pp. 141-164). Nueva York: Praeger.

Moltó Calvo, M. A. (1980). La economía irregular: una primera aproximación al caso español. Revista Española de Economía, 3, 33-52.

Oficina Internacional del Trabajo (s. f.). Medición de la economía informal. Recuperado de http://studyres. es/doc/1283068/medici \%C3 \%B3n-de-laeconom \%C3 \%ADa-informal

Pickhardt, M. y Sardà, J. (2015). Size and causes of the underground economy in Spain: A correction of the record and new evidence from the MCDR approach. European Journal of Law and Economics, 39(2), 403429.

Ramos Álvarez, M. M. (s. f.). Curso de recursos metodológicos y estadísticos. Recuperado de http:// www4.ujaen.es/ mramos/Cursos/RMEDI/T01 ModAnali.pdf

Resolución sobre las estadísticas del empleo en el sector informal, adoptada por la decimoquinta Conferencia Internacional de Estadísticos del Trabajo (enero de 1993).

Reynolds, P., Bygrave, W. D., Autio, E. y Hay, M. (2002). Global entrepreneurship monitor: 2002 executive monitor. Londres: London Business School.
Serrano Sanz, J.M. (2010). Economía bajo la superficie en VV.AA.: Implicaciones de la economía sumergida en España. Círculo de Empresarios, Libro Marrón. Madrid, España.

Sarda Pons, J. (dir.) (2014). La economía sumergida pasa factura: el avance del fraude en España durante la crisis. Técnicos del Ministerio de Hacienda (Gestha) y Universitat Rovira $i$ Virgili. Recuperad de http://www.gestha.es/ archivos/actualidad/2014/2014-01-29 INFORME

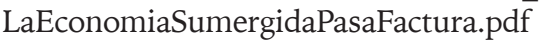

Sarda Pons, J. y Mauleón Torres, I. (1997). Estimación cuantitativa de la economía sumergida en España. Ekonomiaz: Revista vasca de economía, 39, 124-135.

Schneider, F. (1997). El tamaño de la economía sumergida en los países de Europa occidental. Ekonomiaz, 39, 136-151.

Schneider, F. (2015). Size and Development of the Shadow Economy of 31 European and 5 Other OECD Countries from 2003 to 2014: Different Developments? Journal of Self-Governance $\mathcal{E}$ Management Economics, 3(4), 7-29.

Schneider, F., Buehn, A. y Montenegro, C. E. (2011). Shadow economies all over the world: New estimates for 162 countries from 1999 to 2007. En F. Schneider (ed.), Handbook on the shadow economy (pp. 9-77). Cheltenham, UK: Edward Elgar.

Schneider, F. y Enste, D. H. (2000). Shadow economies: size, causes, and consequences. Journal of Economic Literature, 38(1), 77-114.

Singh, G. y DeNoble, A. (2003). Early retirees as the next generation of entrepreneurs. Entrepreneurship Theory and Practice, 27(3), 207-226.

Snyder, K. A. (2004). Routes to the informal economy in New York's East village: Crisis, economics and identity. Sociological Perspectives, 47, 215-240.

Williams, C. C. (2009). The hidden enterprise culture: Entrepreneurs in the underground economy in England, Ukraine and Russia. Journal of Applied Management and Entrepreneurship, 14(2), 44-60.

Williams, C. C. y Nadin, S. (2010). Entrepreneurship and the informal economy: An overview. Journal of Developmental Entrepreneurship, 15(4), 361-378. 


\section{Anexos}

\section{Anexo 1.}

Test de independencia de la variable dependiente con cada una de las independientes

\section{Registrada/motivación}

\begin{tabular}{|l|c|c|c|c|c|}
\hline & Value & df & $\begin{array}{c}\text { Asymp. Sig. } \\
(2 \text {-sided })\end{array}$ & $\begin{array}{c}\text { Exact Sig. } \\
\text { (2-sided) }\end{array}$ & $\begin{array}{c}\text { Exact Sig. } \\
\text { (1-sided) }\end{array}$ \\
\hline Pearson Chi-Square & $11,953^{\mathrm{a}}$ & 1 &, 001 & & \\
\hline Continuity Correction ${ }^{\mathrm{b}}$ & 11,547 & 1 &, 001 & & \\
\hline Likelihood Ratio & 11,492 & 1 &, 001 & &, 000 \\
\hline Fisher's Exact Test & & & &, 001 & \\
\hline Linear-by-Linear Association & 11,948 & 1 &, 001 & & \\
\hline N of Valid Cases & 2699 & & & & \\
\hline \\
a. 0 cells (,0 \%) have expected count less than 5. The minimum expected count is 114,80. \\
\hline b. Computed only for a 2x2 table \\
\hline
\end{tabular}

\section{Registrada/fase}

\begin{tabular}{|l|c|c|c|}
\hline Chi-Square Tests \\
\hline & Value & df & Asymp. Sig. (2-sided) \\
\hline Pearson Chi-Square & $951,628^{\mathrm{a}}$ & 2 &, 000 \\
\hline Likelihood Ratio & 798,093 & 2 &, 000 \\
\hline Linear-by-Linear Association & 878,546 & 1 &, 000 \\
\hline N of Valid Cases & 2951 & & \\
\hline a. 0 cells (,0 \%) have expected count less than 5. The minimum expected count is 77,68. \\
\hline
\end{tabular}

\section{Registrada/nacionalidad}

\begin{tabular}{|c|c|c|c|c|c|}
\hline \multicolumn{6}{|l|}{ Chi-Square Tests } \\
\hline & Value & df & $\begin{array}{l}\text { Asymp. Sig. } \\
\text { (2-sided) }\end{array}$ & $\begin{array}{l}\text { Exact Sig. } \\
\text { (2-sided) }\end{array}$ & $\begin{array}{l}\text { Exact Sig. } \\
\text { (1-sided) }\end{array}$ \\
\hline Pearson Chi-Square & $9,949^{a}$ & 1 & ,002 & & \\
\hline Continuity Correction ${ }^{\mathrm{b}}$ & 9,244 & 1 & ,002 & & \\
\hline Likelihood Ratio & 8,814 & 1 &, 003 & & \\
\hline Fisher's Exact Test & & & & ,003 & ,002 \\
\hline $\begin{array}{l}\text { Linear-by-Linear } \\
\text { Association }\end{array}$ & 9,945 & 1 & ,002 & & \\
\hline
\end{tabular}


Emprendimiento y economía informal: caracterización empírica de la empresa española a partir de los datos del Global Entrepreneurship Monitor. Pp 15 - 41

\begin{tabular}{|l|l|l|l|l|}
\hline N of Valid Cases & 2979 & & & \\
\hline \\
a. 0 cells $(, 0 \%)$ have expected count less than 5 . The minimum expected count is $24,14$. \\
b. Computed only for a $2 \times 2$ table \\
b.
\end{tabular}

\section{Registrada/género}

\begin{tabular}{|c|c|c|c|c|c|}
\hline \multicolumn{6}{|l|}{ Chi-Square Tests } \\
\hline & Value & df & $\begin{array}{l}\text { Asymp. Sig. } \\
\text { (2-sided) }\end{array}$ & $\begin{array}{l}\text { Exact Sig. } \\
\text { (2-sided) }\end{array}$ & $\begin{array}{l}\text { Exact Sig. } \\
\text { (1-sided) }\end{array}$ \\
\hline Pearson Chi-Square &, $233^{a}$ & 1 & 629 & & \\
\hline Continuity Correction ${ }^{\mathrm{b}}$ &, 186 & 1 & ,667 & & \\
\hline Likelihood Ratio & ,232 & 1 &, 630 & & \\
\hline Fisher's Exact Test & & & & ,641 &, 332 \\
\hline $\begin{array}{l}\text { Linear-by-Linear } \\
\text { Association }\end{array}$ & ,233 & 1 & 629 & & \\
\hline $\mathrm{N}$ of Valid Cases & 2991 & & & & \\
\hline
\end{tabular}

\section{Registrada/edad_corte 42 años}

\begin{tabular}{|c|c|c|c|c|c|}
\hline \multicolumn{6}{|l|}{ Chi-Square Tests } \\
\hline & Value & $\mathrm{df}$ & $\begin{array}{l}\text { Asymp. Sig. } \\
\text { (2-sided) }\end{array}$ & $\begin{array}{l}\text { Exact Sig. } \\
\text { (2-sided) }\end{array}$ & $\begin{array}{l}\text { Exact Sig. } \\
\text { (1-sided) }\end{array}$ \\
\hline Pearson Chi-Square & $99,843^{\mathrm{a}}$ & 1 & ,000 & & \\
\hline Continuity Correction ${ }^{\mathrm{b}}$ & 98,818 & 1 & ,000 & & \\
\hline Likelihood Ratio & 97,597 & 1 & ,000 & & \\
\hline Fisher's Exact Test & & & & ,000 & 000 \\
\hline $\begin{array}{l}\text { Linear-by-Linear } \\
\text { Association }\end{array}$ & 99,809 & 1 & ,000 & & \\
\hline $\mathrm{N}$ of Valid Cases & 2991 & & & & \\
\hline \multicolumn{6}{|c|}{ a. 0 cells $(, 0 \%)$ have expected count less than 5 . The minimum expected count is 185,81 . } \\
\hline \multicolumn{6}{|c|}{ b. Computed only for a $2 \times 2$ table } \\
\hline
\end{tabular}

\section{Registrada/formación universitaria}

\begin{tabular}{|l|c|c|c|c|c|}
\hline \multicolumn{1}{|l|}{ Chi-Square Tests } & Value & df & $\begin{array}{c}\text { Asymp. Sig. } \\
(2 \text {-sided })\end{array}$ & $\begin{array}{c}\text { Exact Sig. } \\
(2 \text {-sided })\end{array}$ & $\begin{array}{c}\text { Exact Sig. } \\
\text { (1-sided) }\end{array}$ \\
\hline Pearson Chi-Square & $11,106^{\mathrm{a}}$ & 1 &, 001 & & \\
\hline Continuity Correction $^{\mathrm{b}}$ & 10,747 & 1 &, 001 & & \\
\hline Likelihood Ratio & 10,807 & 1 &, 001 & & \\
\hline Fisher's Exact Test & & & &, 001 &, 001 \\
\hline
\end{tabular}




\begin{tabular}{|c|c|c|c|c|c|}
\hline Linear-by-Linear Association & 11,102 & 1 & 001 & & \\
\hline $\mathrm{N}$ of Valid Cases & 2991 & & & & \\
\hline \multicolumn{6}{|c|}{ a. 0 cells $(, 0 \%)$ have expected count less than 5 . The minimum expected count is 146,30 . } \\
\hline \multicolumn{6}{|l|}{ b. Computed only for a $2 \times 2$ table } \\
\hline
\end{tabular}

\section{Registrada/sector servicios}

\begin{tabular}{|l|c|c|c|c|c|}
\hline \multicolumn{7}{|l|}{ Chi-Square Tests } & Value & $\mathrm{df}$ & $\begin{array}{c}\text { Asymp. Sig. } \\
(2 \text {-sided })\end{array}$ & $\begin{array}{c}\text { Exact Sig. } \\
(2 \text {-sided })\end{array}$ & $\begin{array}{c}\text { Exact Sig. } \\
\text { (1-sided) }\end{array}$ \\
\hline Pearson Chi-Square & $30,846^{\mathrm{a}}$ & 1 &, 000 & & \\
\hline Continuity Correction ${ }^{\mathrm{b}}$ & 30,257 & 1 &, 000 &, 000 &, 000 \\
\hline Likelihood Ratio & 32,530 & 1 &, 000 & & \\
\hline Fisher's Exact Test & & & & & \\
\hline $\begin{array}{l}\text { Linear-by-Linear } \\
\text { Association }\end{array}$ & 30,836 & 1 & 000 & & \\
\hline N of Valid Cases & 2936 & & & \\
\hline \\
a. 0 cells (,0 \%) have expected count less than 5. The minimum expected count is 160,09. \\
\hline \\
b. Computed only for a 2x2 table \\
\hline
\end{tabular}

\section{Registrada/renta_corte $30000 €$}

\begin{tabular}{|c|c|c|c|c|c|}
\hline \multicolumn{6}{|l|}{ Chi-Square Tests } \\
\hline & Value & df & $\begin{array}{l}\text { Asymp. Sig. } \\
\text { (2-sided) }\end{array}$ & $\begin{array}{l}\text { Exact Sig. } \\
\text { (2-sided) }\end{array}$ & $\begin{array}{l}\text { Exact Sig. } \\
\text { (1-sided) }\end{array}$ \\
\hline Pearson Chi-Square & $3,239^{\mathrm{a}}$ & 1 & 072 & & \\
\hline Continuity Correction ${ }^{\mathrm{b}}$ & 3,022 & 1 & 082 & & \\
\hline Likelihood Ratio & 3,203 & 1 & 074 & & \\
\hline Fisher's Exact Test & & & & 075 & 042 \\
\hline $\begin{array}{l}\text { Linear-by-Linear } \\
\text { Association }\end{array}$ & 3,238 & 1 & 072 & & \\
\hline $\mathrm{N}$ of Valid Cases & 1873 & & & & \\
\hline \multicolumn{6}{|c|}{ a. 0 cells $(, 0 \%)$ have expected count less than 5 . The minimum expected count is 128,35 . } \\
\hline \multicolumn{6}{|c|}{ b. Computed only for a $2 \times 2$ table } \\
\hline
\end{tabular}

\section{Registrada/CCAA limpias}

\begin{tabular}{|c|c|c|c|c|c|}
\hline \multicolumn{6}{|l|}{ Chi-Square Tests } \\
\hline & Value & $\mathrm{df}$ & $\begin{array}{l}\text { Asymp. Sig. } \\
\text { (2-sided) }\end{array}$ & $\begin{array}{l}\text { Exact Sig. } \\
\text { (2-sided) }\end{array}$ & $\begin{array}{l}\text { Exact Sig. } \\
\text { (1-sided) }\end{array}$ \\
\hline Pearson Chi-Square & $7,578^{\mathrm{a}}$ & 1 & ,006 & & \\
\hline Continuity Correction ${ }^{\mathrm{b}}$ & 7,274 & 1 &, 007 & & \\
\hline Likelihood Ratio & 7,841 & 1 & ,005 & & \\
\hline
\end{tabular}


Emprendimiento y economía informal: caracterización empírica de la empresa española a partir de los datos del Global Entrepreneurship Monitor. Pp 15 - 41

\begin{tabular}{|l|c|c|c|c|c|}
\hline Fisher's Exact Test & & & &, 006 &, 003 \\
\hline Linear-by-Linear Association & 7,576 & 1 &, 006 & & \\
\hline N of Valid Cases & 2991 & & & & \\
\hline \\
a. 0 cells (,0\%) have expected count less than 5. The minimum expected count is 132,66. \\
b. Computed only for a 2x2 table \\
\hline
\end{tabular}

Anexo 2.

Prueba de Hosmer and Lemeshow - modelo A

\begin{tabular}{|c|c|c|c|}
\hline \multicolumn{5}{|c|}{ Hosmer and Lemeshow Test } \\
\hline Step & Chi-square & df & Sig. \\
\hline 1 & 9,485 & 8 &, 303 \\
\hline
\end{tabular}

Anexo 3.

Prueba de Hosmer and Lemeshow - modelo B

\begin{tabular}{|c|c|c|c|}
\hline \multicolumn{5}{|c|}{ Hosmer and Lemeshow Test } \\
\hline Step & Chi-square & df & Sig. \\
\hline 1 & 2,620 & 8 &, 956 \\
\hline
\end{tabular}

